\title{
Hybrid Materials: To Revolutionize Decontamination of Groundwater from Various Micro Pollutants Including Radionuclides
}

R K Singhal*

Analytical Chemistry Division, Bhabha Atomic Research Centre, Mumbai, India

*Corresponding author: Singhal RK, Analytical Chemistry Division, Bhabha Atomic Research Centre, Mumbai, India, Tel: +91-22-25505050; E-mail: rsinghal@barc.gov.in

Rec date: November 27, 2014, Acc date: December 01, 2014, Pub date: December 03, 2014

Copyright: () 2014 Singhal RK, This is an open-access article distributed under the terms of the Creative Commons Attribution License, which permits unrestricted use, distribution, and reproduction in any medium, provided the original author and source are credited

Keywords: Micro pollutants; Radionuclides; Hybrid materials; Wastewater treatment

\section{Editorial}

The removal of low levels of micro pollutants $(\mathrm{Cu}, \mathrm{Pb}, \mathrm{Hg}, \mathrm{As}, \mathrm{Cr}$ etc.) and radionuclides ( $\mathrm{U}, \mathrm{Th}, \mathrm{Am}, \mathrm{Pa})$ in various forms in groundwater remains a problem, both technically and economically. Depending on local geology, groundwater contains heavy metals in low levels ( $\mu \mathrm{g} \mathrm{L}^{-1}$ range), but sometimes in concentrations which are not acceptable for drinking water. The high sorption capability exhibited by many biogenic materials such as algae, bacteria, and yeasts or geological materials like silicate and aluminate could be exploited to develop a cost effective method for treating such waters. These geogenic and biogenic matrices can be tailored by chemical modification to make them specific to some metal ions or radionuclides and to enhance their sorption Capacities. Materials used for the sorption of heavy metals from water in commercial applications must be immobilized in order to meet technical demands. Generally, packed bed columns, with a stable, porous material that has a specific grain size, are used. Moreover, tailored materials must be stable and resistant to the medium that is investigated so that there is no release of constituent components. Algae appear to be one of the very promising materials in this regard. Dried algae or even algal extraction residues can be used as sorption material or for immobilizing the specific sorbent.

Clay and minerals are also natural porous materials and are used widely in decontamination of inorganic pollutants from wastewaters however; show insignificant applicability in the treatment of several organic pollutants having low polarity. Mainly this is limited as clay materials are having exchangeable cations, hence this could be exchanged with the organocations. Therefore, the modified materials possess an enhanced organophilicity and this, perhaps, be effective in attenuation of several organic pollutants from aqueous solutions.

The hybrid materials synthesis by impregnating organic material in inorganic matrices or vice versa shows enhances applicability in wastewater treatment. Since this could not only be effective in the removal of inorganic pollutants but also show fair affinity towards the organic impurities as well. Furthermore, these hybrid materials do not have any solubility in ground water in the $\mathrm{pH}$ range $5.4-8.3$. In view of this they can easily be separated from the process water. In general, these materials possess two different sorption sites enabling both organic and inorganic pollutants to be removed from aqueous solutions simultaneously.
The sorption behavior (selectivity and capacity) of a component depends on the availability of binding sites on its surface. Combining a ceramic- like oxide matrix with biological systems offers important advantages. Displacement reactions are used for immobilizing different materials in biogenic and geogenic matrices. The resultant hybrid material is normally characterized by using various techniques like Zeta-sizer for size characterization, SEM-EDS, FTIR and XRD for the surface and structural characterization. The porosity and the degree of immobilization of the embedded materials can be controlled over a wide range of concentration. Homogeneous distribution of the embedded biogenic material within the geogenic matrices is ensured by using surface morphological techniques (SEM-EDS). The stability of the prepared hybrid material and changes in the particle size distribution has to be monitored with time. Kinetics and sorption capacities for various combinations of hybrid materials are also evaluated.

One of the major advantages of these hybrid materials is the ease with which sorbed material will be desorbed using desired eluent. Therefore, in the eluent, detailed analysis of various metal ions is carried out by using absorption/emission spectroscopy while the ultratrace level of radionuclides is measured by using gamma and alpha spectrometry. Second major advantage associated with these hybrid materials is that they will not leach into experimental solution. This can be verified by quantifying various drinking water quality parameters after decontamination. This will ensure the safe consumption of drinking water by human beings.

Some of hybrid material which was already practiced by our group is (a) Sorption of thorium and uranium on siliceous surfaces modified by the association of high molecular weight organic compound (Humic and fulvic). This association in terms depends on the relative abundance and binding energies of functional groups of organic compound. Limited reversibility as observed in case of fulvic acid compared to humic acid leads to a lower sorption of thorium; (b) Sorption of uranium from potable water using organic-organic hybrid material synthesis by impregnated Chlorella (Chlorella pyrendoidosa), a fresh water algae, in calcium alginate (c) Removal of Fluoride from potable water using alumina impregnated in calcium alginate. Besides this there are numbers of other hybrid materials used for removal of traces of $\mathrm{As}, \mathrm{Hg}, \mathrm{Pb}, \mathrm{Pu}-239+240$ and $\mathrm{Am}-241$ from potable water

However there are certain areas which need further strengthening for the use of hybrid materials like the evaluation of composite structure and metal-binding capacity of different types of immobilized materials with regard to their use for the selective and reversible accumulation of heavy metals and radionuclides. 